\title{
PENGELOLAAN KEUANGAN DAN STRATEGI PROMOSI PADA UMKM PECI BATIK JOGOKARIYAN YOGYAKARTA
}

\author{
Agus Dwi Cahya \\ Program Studi Manajemen Universitas Sarjanawiyata Tamansiswa \\ agusdc@ustjogja.ac.id \\ Abdul Aziz Suryadi \\ Program Studi Manajemen Universitas Sarjanawiyata Tamansiswa \\ suryadiaziz08@gmail.com \\ Sherfina Tabatini Evany \\ Program Studi Manajemen Universitas Sarjanawiyata Tamansiswa \\ evanysherfina@gmail.com
}

Masuk : 06-04-2021, revisi : 11-05-2021, diterima untuk diterbitkan : 20-05-2021

\begin{abstract}
This research deals with financial management and promotion strategies in UMKM. Here the researchers chose the "Peci Batik Jogokariyan" UMKM. The purpose of this research is to find out how the management is carried out by the UMKM "Peci Batik Jogokariyan" and how the promotion strategies are carried out. Good UMKM is UMKM that carry out good and correct financial management and UMKM that have efficient promotional strategies. Financial management and promotional strategies are essential for increasing UMKM sales and the future development of UMKM. However, some UMKM has not carried out good and correct financial management and there are still many UMKM that do not have an efficient promotion strategy so that it becomes an obstacle for the development of these UMKM. However, in this study, the researchers obtained the results of the interview that UMKM "Peci Batik Jogokariyan" already has good and correct financial reports and has carried out an efficient promotion strategy so that they can continue to develop for UMKM. The data technique uses documentation, interviews, and observations and this type of research is descriptive exploratory.
\end{abstract}

Keywords: UMKM, Financial Management, Promotion Strategy

Abstrak: Penelitian ini berkaitan dengan pengelolaan keuangan dan strategi promosi dalam UMKM. Di sini peneliti memilih UMKM "Peci Batik Jogokariyan". Tujuan dari penelitian ini adalah untuk mengetahui bagaimana pengelolaan yang dilakukan oleh UMKM "Peci Batik Jogokariyan" dan bagaimana strategi promosi yang dilakukan. UMKM yang baik adalah UMKM yang melakukan pengelolaan keuangan yang baik dan benar serta UMKM yang memiliki strategi promosi yang efisien. Pengelolaan keuangan dan strategi promosi merupakan hal yang penting bagi peningkatan penjualan UMKM serta perkembangan UMKM kedepannya. Namun beberapa UMKM belum melakukan pengelolaan keuangan yang baik dan benar serta masih banyak UMKM yang belum memiliki strategi promosi yang efisien sehingga itu menjadi kendala bagi perkembangan UMKM tersebut. Namun dalam penelitian ini, peneliti mendapatkan hasil wawancara bahwa UMKM Peci Batik Jogokariyan telah memiliki laporan keuangan yang baik dan benar serta telah melakukan strategi promosi yang efisien sehingga bisa terus melakukan perkembangan bagi UMKM. Teknik pengumpulan data dalam penelitian ini dengan dokumentasi, wawancara, dan observasi jenis penelitian ini eksploratif deskriptif.

Kata Kunci: UMKM, Pengelolaan Keuangan, Strategi Promosi 


\section{PENDAHULUAN}

Usaha mikro kecil menengah (UMKM) adalah usaha perdagangan yang dikelola oleh badan usaha atau perorangan yang merujuk pada ekonomi kreatif. UMKM juga merupakan salah satu pendorong proses peningkatan ekonomi Indonesia beberapa tahun belakangan ini. Sejalan dengan sosialisasi hukum yang dilakukan otonomi daerah, semua pemerintah daerah bersaing menggali potensi daerahnya yang berarti mendukung pendapatan asli daerah (PAD). Salah satu potensi yang akan digali yaitu industri kreatif yang memiliki potensial yang tinggi untuk dibangun dan dikembangkan. Dengan industri kreatif ini nantinya akan meningkatkan taraf hidup masyarakat (Azizah et al., 2019).

Namun, seiring perkembangan UMKM masih sering terjadi beberapa masalah, disini peran pemerintah sangat dibutuhkan agar UMKM terus bisa eksis membantu perekonomian Negara. Dengan diadakannya program pelatihan bagi para UMKM misalnya, bagaimana mengelola keuangan dalam UMKM yang benar serta bagaimana strategi promosi yang baik agar UMKM tersebut bisa terus mengembangkan produk-produknya. Karena masih banyak UMKM yang belum benar-benar menerapkan pengelolaan yang baik serta belum memiliki strategi promosi yang ideal. Maka dari itu, dengan pelatihan pengelolaan keuangan yang baik dari pemerintah akan berdampak positif pada strategi promosi bagi UMKM tersebut.

Kemudian, disini peneliti memilih UMKM yang dapat diangkat di wilayah Jogakariyan, Mantrijeron Yogyakarta adalah UMKM "Peci Batik Jogokariyan". UMKM ini sudah memiliki karyawan sebanyak 26, dari 26 karyawan ini sudah memiliki bagian masing-masing antara lain bagian produksi, marketing online dan bagian accounting. Di UMKM Peci Batik ini, peneliti akan meneliti bagaimana pengelolaan keuangan yang dilakukan serta bagimana strategi promosi yang diterapkan. Tujuan dari penelitian ini adalah untuk mengetahui bagaimana pengelolaan keuangan dan bagaimana strategi yang dilakukan oleh UMKM Peci Batik Jogokariyan, Yogyakarta.

\section{LANDASAN TEORI Pengertian UMKM}

Usaha Mikro Kecil Menengah merupakan salah satu penggerak perekonomian bangsa karena memegang peranan penting dalam pertumbuhan dan penyerapan tenaga kerja di Indonesia (Ningtyas, 2017). UMKM merupakan pelaku bisnis yang bergerak pada berbagai bidang usaha, yang menyentuh kepentingan masyarakat. Tujuan dari UMKM yakni meningkatkan perekonomian masyarakat dengan penyerapan tenaga kerja, sehingga bisa mengurangi tingkat pengangguran yang tinggi. Dalam upaya meningkatkan kemajuan UMKM ada beberapa faktor yang harus diperhatikan agar UMKM semakin berkembang dan tetap bertahan (Mulyani, 2014). Beberapa faktor dari UMKM yaitu tentang pengelolaan keuangan dan strategi promosinya.

\section{Pengelolaan Keuangan}

Dalam pengelolaan keuangan terdapat beberapa indikator diantaranya perencanaan, pencatatan dan pelaporan keuangan. Pengelolaan keuangan yang baik akan berpengaruh pada peningkatan kinerja usaha dan peningkatan daya saing. Pada umumnya, pengelolaan keuangan UMKM berjalan tanpa mengandalkan informasi akuntansi yang disusun secara terstruktur akan tetapi cenderung didasarkan pada intuisi atau kebiasaan yang berasal dari pengalaman di masa lalu (Puspitaningtyas, 2017). Kebanyakan UMKM masih pasif dalam mengelola keuangannya sehingga hal tersebut bisa menimbulkan masalah kedepannya bagi UMKM. Pengelolaan yang baik bisa dilihat dari segi manajemen keuangan yang ada dalam UMKM.

Kemudian Anggraeni (2016) dalam Suindari dan Juniariani (2020), pengelolaan keuangan adalah segala aktivitas yang berhubungan dengan perolehan, pendanaan dan pengelolaan aktiva dengan beberapa tujuan menyeluruh. Seluruh proses tersebut dilakukan untuk mendapatkan pendapatan perusahaan dengan meminimalkan biaya, selain itu dalam penggunaan dan pengalokasian dana yang efisien dan dapat memaksimalkan nilai perusahaan. 
Sejatinya pengelolaan keuangan sangat mempengaruhi kinerja perusahaan, seperti yang dijelaskan oleh Anggraeni (Anggraeni, 2016) dalam Suindari dan Juniariani (2020) menyatakan bahwa profesionalisme dalam pengelolaan keuangan aan membantu pelaku usaha terkait dengan pengelolaan usaha dimulai dari anggaran, perencanaan simpanan usaha serta pengetahuan dasar atas keuangan untuk mencapai tujuan keuangan usaha. Dalam mengelola sebuah usaha perlu pengelolaan keuangan yang baik agar menghasilkan kinerja yang baik pula. Dengan kinerja yang baik maka UMKM kedepannya bisa terus berkembang.

\section{Strategi Promosi}

Promosi berarti aktivitas yang menyampaikan produk dan membujuk pelanggan untuk membelinya. Lalu menurut Kotler (2005) dalam Wibowo et al. (2015), promosi adalah berbagai kegiatan yang dilakukan oleh produsen untuk mengkomunikasikan manfaat dari produknya, membujuk dan mengingatkan para konsumen agar membeli produk tersebut.

Strategi pemasaran adalah salah satu cara untuk memenangkan keunggulan bersaing yang berkesinambungan baik itu untuk perusahaan yang memproduksi barang atau jasa. Strategi pemasaran dapat dipandang sebagai salah satu dasar yang dipakai dalam menyusun perencanaan UMKM secara menyeluruh. Dipandang dari luasnya permasalahan yang ada dalam suatu usaha, maka diperlukan adanya perencanaan yang menyeluruh untuk dijadikan pedoman bagi segmen suatu usaha dalam menjalankan kegiatannya (Arifen et al., 2019). Menurut Warnadi dan Triyono (2019) dalam Tabroni dan Komarudin (2021), kegiatan promosi merupakan kegiatan yang digunakan perusahaan untuk menyebarkan informasi untuk ditujukan kepada konsumen. Promosi diartikan sebagai koordinasi dari keseluruhan upaya yang dimulai pihak penjual (produsen) untuk membangun berbagai saluran informasi dan persuasi untuk menjual barang dan jasa atau memperkenalkan suatu gagasan.

Promosi yang dilakukan melalui sistem online interaktif yang menghubungkan pembeli dan penjual secara elektronik, merupakan bagian terpenting dari e-commerce atau proses perdagangan secara elektronik dengan menggunakan website, blog atau media sosial (Setiawati \& Widyartati, 2017) . Dalam strategi promosi UMKM di era milenial ini, banyak anak muda yang lebih tertarik jika produk-produk yang ditawarkan menggunakan influencer atau para selebgram lebih tepatnya disebut juga endorsement. Itu menjadi salah satu strategi yang ampuh bagi UMKM agar produk-produknya bisa laris di kalangan masyarakat. Kemudian strategi dalam media sosial sangat berperan agar barang dagangan maupun jasa yang ditawarkan para pebisnis UMKM mendapat jangkauan yang luas kepada masyarakat. Selain itu strategi ini dibutuhkan dalam memenangkan pangsa pasar di media sosial (Permana \& Cendana, 2019).

\section{METODE PENELITIAN}

Metode penelitian ini menggunakan pendekatan deskriptif kualitatif, yang mendasarkan dengan observasi dan wawancara dengan informan (Puspitaningtyas, 2017). Populasi dan sampel dalam penelitian ini adalah Pemilik UMKM "Peci Batik Jogokariyan" yang dalam penelitian ini menjadi narasumber atau informan dari penelitian. Teknik pengumpulan data dilakukan melalui kegiatan observasi, dokumentasi dan wawancara. Teknik analisis data dilakukan dengan cara reduksi data dan penarikan kesimpulan (Mandasari et al., 2019).

\section{HASIL DAN PEMBAHASAN}

\section{Pengelolaan Keuangan}

Dimulai sejak awal berdiri UMKM Peci Batik Jogokariyan tersebut, Bapak Jardi selaku pelaku usaha belum menggunakan pelaporan keuangan dengan pembukuan melainkan hanya memutar setiap uang yang ada untuk membeli bahan baku, seiring berjalannya usaha tersebut beliau menggunakan catatan pembukuan secara manual yaitu dengan 3 poin didalamnya yang pertama pemasukan, pengeluaran dan balance. Tahun 2018, Pak Jardi mengikuti pelatihan dari Pemerintah Kota Yogyakarta lebih tepatnya Dinas Koperasi. Beliau diajarkan bagaimana pencatatan pembukuan keuangan secara baik dan benar. Namun setelah mendapatkan program 
dari pemerintah, Pak Jardi belum menguasai atau belum maksimal dalam pengelolaannya. Di tahun 2019, Pak Jardi mulai menerapkan pelatihan yang diberikan oleh pemerintah kota. Tepat di tahun 2020 bulan September, beliau merekrut seseorang untuk dijadikan accounting dan sebelumnya Pak Jardi memberi pelatihan terlebih dahulu kepada calon accounting tersebut. Hal tersebut didukung dalam penelitian terdahulu yang dilakukan oleh Erawan dan Hamdani (2017) dalam Saputra et al. (2018) yang menyatakan bahwa pengelolaan keuangan usaha yang berskala mikro, melakukan peningkatan kapasitas sumber daya manusia dengan pelaksanaan pelatihan dan pendidikan bagi karyawan. Kemudian accounting yang direkrut oleh Pak Jardi tersebut membantu dalam proses pembukuan usaha Pak Jardi. Pencatatan transaksi dilakukan setiap hari sedangkan proses penutupannya dilakukan secara perbulan dan di akhir tahun dilakukan pembukuan secara tahunan. Dilihat laba kotor bahkan laba bersih secara setahun. Pengelolaan keuangan yang digunakan oleh accounting yaitu dengan memanfaatkan Microsoft Excel tidak menggunakan program aplikasi apapun.

Salah satu kekurangan dalam pengelolaan keuangan UMKM ini, yaitu belum terpisahnya uang pribadi dan uang usaha, jadi masih menggunakan rekening milik pribadi. Planning kedepannya, beliau akan memisahkan antara uang usaha dengan uang pribadi. Dengan pengelolaan keuangan yang sekarang yang dibantu oleh accounting memudahkan Pak Jardi dalam melihat transaksi-transaksi sehari-hari, memudahkan beliau juga dalam sisi pengontrolan pengeluaran keuangan. Sehingga hal tersebut bisa membuat UMKM Peci Batik Jogokariyan semakin berkembang sebagaimana hal tersebut sama dengan penelitian terdahulu yang terdapat dalam Falih et al. (2019) yaitu bisnis UMKM yang keuangannya dikelola dan diinformasikan secara transparan dan akurat akan memberikan dampak positif terhadap bisnis UMKM itu sendiri. Jika hal ini dapat dilakukan oleh setiap wirausaha, maka besarlah harapan untuk menjadikan usaha yang semula kecil menjadi besar.

\section{Strategi Promosi}

Sejak awal berdiri UMKM Peci Batik ini, pemilik UMKM belum melakukan strategi promosi yang meluas, ia hanya menempatkan produknya ke toko-toko retail yang ada di Jogja sehingga UMKM Peci Batik ini belum begitu memiliki konsumen yang banyak dan untuk lingkup konsumennya masih sempit. Hal ini berimbas pada pendapatan yang diterima karena pendapatannya waktu itu tidak bisa menutup pengeluaran yang dilakukan. Hal itu menyebabkan pada perkembangan UMKM yang tidak bisa meningkat pada waktu itu. Seiring perkembangannya zaman, pemilik UMKM ini yaitu Pak Jardiyanto beralih ke dunia digital dimana beliau mempromosikan produk-produknya lewat digital. Hal ini didukung oleh penelitian terdahulu yang terdapat dalam Pamungkas (2017) dan menghasilkan strategi promosi menggunakan media sosial dinilai menjadi strategi pemasaran yang cukup efektif dan didukung dengan word of mouth yang positif yang mampu menarik konsumen untuk melakukan pembelian.

Awal mula Pak Jardi dan timnya berpindah ke digital yaitu dengan melakukan survei di media sosial untuk mengetahui trend-trend apa saja yang diinginkan oleh konsumen dengan berbagai kategori seperti usia, pendapatan dan juga tingkat pendidikan. Dan dalam waktu dua minggu, Pak Jardi dan timnya pun mendapatkan data untuk menjadi acuan bagi produk-produk nya nanti yang akan dipasarkan. Pak Jardi juga membuka penjualan di e-commerce seperti Shopee, Tokopedia, dan juga di Instagram serta Facebook. Akun Shopee dari UMKM ini bisa dilihat di Kopiah Peci Batik Jogokariyan, kemudian Tokopedia di Peci Batik Jogokariyan, lalu Instagram UMKM Peci Batik Jogokariyan bisa dilihat di @pecibatikjogokariyan serta Facebook bisa dilihat di halaman Peci Batik Jogokariyan. Namun hal tersebut belum terlalu meningkatkan penjualan UMKM milik Pak Jardi. Setelah melakukan survei dan mendapat beberapa pilihan, Pak Jardi memilih strategi untuk promosi produknya dengan endorsement. Pak Jardi melakukan strategi tersebut karena pada salah satu event yang ada di Jogokariyan yaitu Hijrah Fest. Dalam acara tersebut terdapat beberapa artis lokal yang itu memicu ide Pak Jardi untuk memperkenalkan produk peci batiknya kepada artis-artis yang ada di event itu dan 
memulai untuk bekerja sama dengan melakukan endorsement. Hasil yang didapat dengan melakukan endorsement ke artis-artis tersebut tenyata sangat menguntungkan bisnis yang dijalankan oleh Pak Jardi, mulai dari Shopee, Instagram, Facebook dan e-commerce yang lainnya penjualan semakin meningkat. Sehingga hingga saat ini strategi promosi dengan menggunakan endorsement arti-artis terus dilakukan oleh Pak Jardi untuk terus meningkatkan penjualan UMKM Peci Batik.

\section{REFERENSI}

Anggraeni, B. D. (2016). Pengaruh tingkat literasi keuangan pemilik usaha terhadap pengelolaan keuangan. Studi kasus: UMKM Depok. Jurnal Vokasi Indonesia, 3(1), 22 30. https://doi.org/10.7454/jvi.v3i1.23

Arifen, S. R., Purwanty, V. D., Suci, D. A., Agustiawan, R. H., \& Sudrajat, A. R. (2019). Analisis strategi pemasaran untuk meningkatkan daya saing UMKM. Konferensi Nasional Ilmu Administrasi, 1-7. http://180.250.247.102/conference/index.php/knia/article/viewFile/112/pdf

Azizah, N., Mahendra, D., \& Lofian, B. (2019). Pemanfaatan e-commerce untuk peningkatan strategi promosi dan penjualan UMKM tas di Kabupaten Kudus. E-Dimas: Jurnal Pengabdian Kepada Masyarakat, 10(1), 96-99. https://doi.org/10.26877/edimas.v10i1.3555

Erawan, W., \& Hamdani, N. A. (2017). The adoption knowledge management in small and medium-sized enterprises to face ASEAN Ecconomic Community (AEC) on competitive environment. In Sekretariat ASEAN. http://setnasasean.id/site/uploads/document/journals/file/59b0ed8f8c0bd-9-cluster-ekonomi-univgarut.pdf

Falih, M. S. H. Al, Rizqi, R. M., \& Ananda, N. A. (2019). Pengelolaan keuangan dan pengembangan usaha pada usaha mikro kecil menengah (Studi kasus pada UMKM Madu Hutan Lestari Sumbawa). Jurnal Manajemen Dan Bisnis, 2(1), 1-8. https://doi.org/10.37673/jmb.v2i1.302

Kotler, P. (2005). Manajemen pemasaran. PT Indeks Kelompok Gramedia.

Mandasari, D. J., Widodo, J., \& Djaja, S. (2019). Strategi pemasaran usaha mikro, kecil dan menengah (UMKM) Batik Magenda Tamanan Kabupaten Bondowoso. JURNAL PENDIDIKAN EKONOMI: Jurnal Ilmiah Ilmu Pendidikan, Ilmu Ekonomi Dan Ilmu Sosial, 13(1), 123-128. https://doi.org/10.19184/jpe.v13i1.10432

Mulyani, S. (2014). Faktor-faktor yang mempengaruhi kualitas laporan keuangan pada UMKM di Kabupaten Kudus. Jurnal Dinamika Ekonomi \& Bisnis, 11(2), 137-150. https://doi.org/10.34001/jdeb.v11i2.207

Ningtyas, J. D. A. (2017). Penyusunan laporan keuangan UMKM berdasarkan standar akuntansi keuangan entitas mikro, kecil dan menengah (SAK-EMKM) (Study kasus di UMKM Bintang Malam Pekalongan). Riset \& Jurnal Akuntansi, 2(1), 11-17. https://owner.polgan.ac.id/index.php/owner/article/view/28/12

Pamungkas, B. A. (2017). Pengaruh promosi di media sosial dan word of mouth terhadap keputusan pembelian (Studi kasus pada Kedai Bontacos, Jombang). Jurnal Komunikasi, 10(2), 145-159. https://doi.org/10.21107/ilkom.v10i2.2518

Permana, S. D. H., \& Cendana, M. (2019). Pemanfaatan media sosial sebagai strategi promosi bagi kelangsungan UMKM. Journal Community Development and Society, 1, 1-10. https://ejournal.unitomo.ac.id/index.php/pengabdian/article/view/1649/810

Puspitaningtyas, Z. (2017). Pembudayaan pengelolaan keuangan berbasis akuntansi bagi pelaku usaha kecil menengah. Jurnal Akuntansi, 21(3), 361-372.

https://doi.org/10.24912/ja.v21i3.242 
Saputra, K. A. K., Ekajayanti, L. G. P. S., \& Anggiriawan, P. B. (2018). Kompetensi sumber daya manusia dan sikap love of money dalam pengelolaan keuangan usaha mikro kecil menengah (UMKM). Jurnal Reviu Akuntansi Dan Keuangan, 8(2), 135-146. https://doi.org/10.22219/jrak.v8i2.33

Setiawati, I., \& Widyartati, P. (2017). Pengaruh strategi pemasaran online terhadap peningkatan laba UMKM. Strategi Komunikasi Pemasaran, 1(1), 343-347. http://ejurnal.stiedharmaputra-smg.ac.id/index.php/PRO/article/view/263/229

Suindari, N. M., \& Juniariani, N. M. R. (2020). Pengelolaan keuangan, kompetensi sumber daya manusia dan strategi pemasaran dalam mengukur kinerja usaha mikro kecil menengah (UMKM). KRISNA: Kumpulan Riset Akuntansi, 11(2), 148-154. https://doi.org/10.22225/kr.11.2.1423.148-154

Tabroni, \& Komarudin, M. (2021). Strategi promosi produk melalui digital marketing bagi UMKM terdampak pandemi Covid'19 berdasarkan keputusan konsumen. Jurnal Riset Entrepreneurship, 4(1), 49-57. https://doi.org/10.30587/jre.v4i1.2217

Warnadi, \& Triyono, A. (2019). Manajemen pemasaran (I. Astarina (ed.)). CV Budi Utama.

Wibowo, D. H., Arifin, Z., \& Sunarti. (2015). Analisis strategi pemasaran untuk meningkatkan daya saing UMKM (Studi pada Batik Diajeng Solo). Jurnal Administrasi Bisnis (JAB), 29(1), 59-66.

http://administrasibisnis.studentjournal.ub.ac.id/index.php/jab/article/view/1172/1462 